\title{
Genetic Variability of Kernel Provitamin-A in Sub-tropically Adapted Maize Hybrids Possessing Rare Allele of $\beta$-carotene hydroxylase
}

\author{
R. Goswami ${ }^{1}$, R.U. Zunjare ${ }^{1}$, S. Khan ${ }^{2}$, V. Muthusamy ${ }^{1}$, A. Baveja ${ }^{1}$, A.K. Das ${ }^{1}$, S.K. Jaiswal ${ }^{1}$, \\ J.S. BHAT ${ }^{1}$, S.K. GULERIA ${ }^{3}$ and F. HOSSAIN ${ }^{1 *}$ \\ ${ }^{1}$ ICAR-Indian Agricultural Research Institute (IARI), New Delhi, India \\ ${ }^{2}$ Banasthali Vidyapith, Rajasthan, India \\ ${ }^{3}$ CSK-Himachal Pradesh KrishiVishvavidyalaya, Bajaura, India \\ (Received 13 March 2018; Accepted 12 February 2019; \\ Communicated by R.N. Chibbar)
}

\begin{abstract}
Vitamin-A deficiency is a major health concern. Traditional yellow maize possesses low provitamin-A (proA). Mutant $\operatorname{crtRB} 1$ gene significantly enhances proA. 24 experimental hybrids possessing crtRB1 allele were evaluated for $\beta$-carotene (BC), $\beta$-cryptoxanthin (BCX), lutein (LUT), zeaxanthin (ZEA), total carotenoids (TC) and grain yield at multilocations. BC $(0.64-17.24 \mu \mathrm{g} / \mathrm{g}), \mathrm{BCX}(0.45-6.84 \mu \mathrm{g} / \mathrm{g})$, proA $(0.86-20.46 \mu \mathrm{g} / \mathrm{g})$, LUT $(9.60-31.03 \mu \mathrm{g} / \mathrm{g})$, ZEA $(1.24-12.73 \mu \mathrm{g} / \mathrm{g})$ and TC $(20.60-64.02 \mu \mathrm{g} / \mathrm{g})$ showed wide variation. No significant genotype $\times$ location interaction was observed for carotenoids. The mean BC $(8.61 \mu \mathrm{g} / \mathrm{g}), \mathrm{BCX}(4.04 \mu \mathrm{g} / \mathrm{g})$ and proA $(10.63 \mu \mathrm{g} / \mathrm{g})$ in $\mathrm{crtRB} 1$-based hybrids was significantly higher than normal hybrids lacking $c r t R B 1$-favourable allele (BC: $1.73 \mu \mathrm{g} / \mathrm{g}$, BCX: $1.29 \mu \mathrm{g} / \mathrm{g}$ and proA: $2.37 \mu \mathrm{g} / \mathrm{g}$ ). Selected $\mathrm{crtRB} 1$-based hybrids possessed 33\% BC and $40 \%$ BCX compared to $6 \% \mathrm{BC}$ and $5 \% \mathrm{BCX}$ in normal hybrids. $\mathrm{BC}$ showed positive correlation with BCX $(\mathrm{r}=0.90)$, proA $(\mathrm{r}=0.99)$ and $\mathrm{TC}(\mathrm{r}=0.64)$ among crtRBl-based hybrids. Carotenoids didn't show association with grain yield. Average yield potential of proA rich hybrids (6794 kg/ha) was at par with normal hybrids (6961 kg/ha). PROAH-13, PROAH-21, PROAH-17, PROAH-11, PROAH-23, PROAH-24 and PROAH-3 were the most promising with $>12 \mu \mathrm{g} / \mathrm{g}$ proA and $>6000 \mathrm{~kg} / \mathrm{ha}$ grain yield. The newly identified crtRB1-based hybrids assume significance in alleviating malnutrition.
\end{abstract}

Keywords: maize, variability, provitamin-A, biofortification, crtRB1

\section{Introduction}

Malnutrition affects nearly two billion people worldwide (Global Nutrition Report 2017). It contributes to global burden of disease and associated with annual loss in gross domestic product to the extent of $11 \%$ in Africa and Asia. Considering its widespread ramification, Global community in 2015 has framed 'Sustainable Development Goals' (SDGs) where 12 of 17 goals are extremely relevant to nutrition. It is estimated that with $\$ 1$ investment in a proven nutrition programme, benefit of $\$ 16$ is achieved (IFPRI 2016). 
Among various micronutrients, vitamin-A deficiency (VAD) results in visual impairment, and may lead to disorders like night blindness, xerophthalmia and keratomalacia. It affects 4.4 million preschool-age children and 20 million pregnant women. Although various avenues like 'food fortification', 'medical supplementation' and 'dietary diversification' are available, the development of biofortified crops with enhanced micronutrients is the most sustainable and cost-effective way to alleviate malnutrition (Neeraja et al. 2017; Sarika et al. 2018).

Carotenoids derived from plant products have been the major source of provitamin-A (proA) in the human diet (Zunjare et al. 2018a). Cereals are rich source of energy in the form of carbohydrates, but lacks required content of proA carotenoids (Gupta et al. 2015). Among carotenoids, $\alpha$-carotene (AC), $\beta$-carotene (BC) and $\beta$-cryptoxanthin (BCX) serve as the precursor for vitamin-A biosynthesis in humans, while lutein (LUT) and zeaxanthin (ZEA) act as antioxidants (Fraser and Bramley 2004).

Maize serves as an important crop as a source of energy, protein and various minerals and vitamins to millions of people worldwide including India (Gupta et al. 2015). Although yellow maize contains enough kernel carotenoids, it contains only $0.25-2.50$ $\mu \mathrm{g} / \mathrm{g}$ of proA carotenoids which is far below the prescribed daily requirement for humans (Zunjare et al. 2017, 2018a,b,c). Favourable allele of $\beta$-carotene hydroxylase (crtRB1) reduces the conversion of $\beta$-carotene and $\beta$-crypoxanthin (precursors of proA) into other products. Therefore, $c r t R B 1$-favourable allele significantly enhances proA content in maize kernel (Yan et al. 2010). Several countries have now introgressed crtRB1 allele into locally adapted genotypes which led to the development of proA rich hybrids (Bouis and Saltzman 2017). In India, the genetic base of the proA rich maize germplasm is extremely narrow and only one proA rich maize hybrid has been released so far (Muthusamy et al. 2014; Yadava et al. 2017). This warrants development of high yielding maize hybrids rich in proA for diverse agro-ecologies of the country. In the present study, a set of crtRB1-based maize hybrids developed from newly generated inbreds were evaluated at multi-locations to (i) study the effects on $\operatorname{crtRB} 1$ on accumulation of proA in diverse genetic background, (ii) understand the extent of influence of locations on accumulation of proA, and (iv) identify promising proA rich hybrids with high grain yield potential.

\section{Materials and Methods}

\section{Genetic materials}

A total of 35 maize hybrids were selected for present study. Of these, 24 maize hybrids (PROAH-1 to PROHA-24) possessing crtRB1-favourable allele were generated by inbreds developed/selected through marker-assisted selection (MAS) of crtRB1 allele at IARI, New Delhi. PROAH-23 and PROAH-24 are the crtRB1- and opaque2- version of popular hybrids viz., HM4 and HM8, respectively. This set also included 11 checks, of which Pusa Vivek QPM9 Improved and APH27 were crtRB1-based hybrids developed through MAS (Muthusamy et al. 2014). 'Pusa Vivek QPM9 Improved' has been released for commercial cultivation and is the first proA rich hybrid in India. APH27 is under 
Table 1. List of 35 maize hybrids tested in present study

\begin{tabular}{|c|c|c|c|}
\hline S. No. & Maize hybrid & crtRB1-allelic status & Source Institution \\
\hline 1. & HQPM1 & Unfavourable allele & CCSHAU, Karnal \\
\hline 2. & HQPM5 & Unfavourable allele & CCSHAU, Karnal \\
\hline 3. & HQPM4 & Unfavourable allele & CCSHAU, Karnal \\
\hline 4. & HQPM7 & Unfavourable allele & CCSHAU, Karnal \\
\hline 5. & HM9 & Unfavourable allele & CCSHAU, Karnal \\
\hline 6. & HM10 & Unfavourable allele & CCSHAU, Karnal \\
\hline 7. & HM11 & Unfavourable allele & CCSHAU, Karnal \\
\hline 8. & Co-MH6 & Unfavourable allele & TNAU, Coimbatore \\
\hline 9. & AH9003 & Unfavourable allele & IARI, New Delhi \\
\hline 10. & PROAH-1 & Favourable allele & IARI, New Delhi \\
\hline 11. & PROAH-2 & Favourable allele & IARI, New Delhi \\
\hline 12. & PROAH-3 & Favourable allele & IARI, New Delhi \\
\hline 13. & PROAH-4 & Favourable allele & IARI, New Delhi \\
\hline 14. & PROAH-5 & Favourable allele & IARI, New Delhi \\
\hline 15. & PROAH-6 & Favourable allele & IARI, New Delhi \\
\hline 16. & PROAH-7 & Favourable allele & IARI, New Delhi \\
\hline 17. & PROAH-8 & Favourable allele & IARI, New Delhi \\
\hline 18. & PROAH-9 & Favourable allele & IARI, New Delhi \\
\hline 19. & PROAH-10 & Favourable allele & IARI, New Delhi \\
\hline 20. & PROAH-11 & Favourable allele & IARI, New Delhi \\
\hline 21. & PROAH-12 & Favourable allele & IARI, New Delhi \\
\hline 22. & PROAH-13 & Favourable allele & IARI, New Delhi \\
\hline 23. & PROAH-14 & Favourable allele & IARI, New Delhi \\
\hline 24. & PROAH-15 & Favourable allele & IARI, New Delhi \\
\hline 25. & PROAH-16 & Favourable allele & IARI, New Delhi \\
\hline 26. & PROAH-17 & Favourable allele & IARI, New Delhi \\
\hline 27. & PROAH-18 & Favourable allele & IARI, New Delhi \\
\hline 28. & PROAH-19 & Favourable allele & IARI, New Delhi \\
\hline 29 & PROAH-20 & Favourable allele & IARI, New Delhi \\
\hline 30. & PROAH-21 & Favourable allele & IARI, New Delhi \\
\hline 31. & PROAH-22 & Favourable allele & IARI, New Delhi \\
\hline 32. & PROAH-23 & Favourable allele & IARI, New Delhi \\
\hline 33. & PROAH-24 & Favourable allele & IARI, New Delhi \\
\hline 34. & APH27 & Favourable allele & IARI, New Delhi \\
\hline 35. & Pusa Vivek QPM9 Improved & Favourable allele & IARI, New Delhi \\
\hline
\end{tabular}


national testing in All India Coordinated Research Project (AICRP). The other set consisted of eight released [HM9, HM10, HM11, HQPM1, HQPM4, HQPM5 and HQPM7 (CCSHAU, Karnal) and Co-MH6 (TNAU, Coimbatore)] and one pre-released [AH9003 (IARI, New Delhi)] hybrid possessing unfavourable allele of $\operatorname{crtRB} 1$ (Table 1).

\section{Field evaluation}

All these maize hybrids were evaluated under randomised complete block design (RCBD) with two replications at three locations of India, namely (i) HAREC Farm, CSKHPKV, Bajaura, Himachal Pradesh $\left(32^{\circ} 2^{\prime} \mathrm{N}, 77^{\circ} 9^{\prime} \mathrm{E}, 1090 \mathrm{MSL}\right)$; (ii) IARI, Experimental Farm, New Delhi $\left(28^{\circ} 089 \mathrm{~N}, 77^{\circ} 129 \mathrm{E}, 229 \mathrm{MSL}\right)$; and (iii) IARI Regional Research Centre, Dharwad $\left(15^{\circ} 219 \mathrm{~N}, 7^{\circ} 059 \mathrm{E}, 750 \mathrm{MSL}\right)$, Karnataka during rainy season 2015 . These three locations belong to different agroclimatic zones of maize cultivation in India. The Bajaura centre located in Northen Hill Zone (NHZ), while New Delhi and Dharwad centre belong to North Western Plain Zone (NWPZ) and Peninsular Zone (PZ), respectively. Maize is grown in valley and steps of the hills in NHZ, which experiences generally cooler and pleasant climate. The soil in the zone contains high organic matter. In NWPZ, maize is grown in alluvial soil and experiences comparatively hot and sub-humid climate. Maize in the PZ is grown in both red and black soil, which possesses hot and humid climate. This zone is generally water scarce and drought prone region. The hybrids were grown in $3 \mathrm{~m}$ row with spacing row-to-row and plant-to-plant spacing of $75 \mathrm{~cm}$ and 20 $\mathrm{cm}$, respectively. Recommended cultural practices were followed to raise the crop. Two to three plants in each replication of all entries were self-pollinated to avoid any possible contamination from foreign pollen. Grain yield per plot was taken from open-pollinated plants per entry, and further converted to tonnes/hectare $(\mathrm{t} / \mathrm{ha})$.

\section{Carotenoid extraction and quantification}

The extraction and quantification of carotenoids were undertaken as per Zunjare et al. (2018a). Selfed ears with husk were harvested individually, and dried for seven days under shade. Seeds were then packed in polythene packets and kept in $-20{ }^{\circ} \mathrm{C}$ freezer till carotenoids estimation. Fine flour powder of 20-25 self-fertilised seeds from each ear of hybrid were used for carotenoid profiling. Sample preparation was done under dark conditions to avoid loss of carotenoids. Samples were eluted through YMC Carotenoid C30 column $(5 \mu \mathrm{m}, 4.6 \times 250 \mathrm{~mm}$; YMC) and detected with a diode array detector-3000 (RS) of Dionex Ultimate 3000 UHPLC System (Ultra High Performance Liquid Chromatography; Thermo Fisher Scientific, US). Six dilutions of each of BC, BCX, LUT and ZEA standard (Sigma Aldrich, USA) were used to make the standard regression curves. These regression curves were used to calculate the carotenoid concentration of the hybrids. The proA concentration was calculated as sum of BC plus half the BCX (Muthusamy et al. 2014). While all carotenoids were added to calculate total carotenoids (TC). 


\section{Statistical analyses}

The carotenoids (BC, BCX, proA, LUT, ZEA and TC) and grain yield data were analysed for analysis of variance (ANOVA) using Windostat version 8.5 (Indostat services, Hyderabad). Correlation coefficients (r) among the traits and its statistical significance were computed through IBM-SPSS version 20 software package (IBM Corporation, New York, US).

\section{Results}

Genetic variability for kernel carotenoids

ANOVA revealed significant variation in hybrids for BC, BCX, proA, LUT, ZEA and TC, and genotypes contributed $68.1-83.9 \%$ of the total variance across carotenoid fractions (Table 2). Significant effect of location was observed only for LUT, ZEA and TC. However, variation due to location among carotenoid fractions accounted only $0.2-7.5 \%$ of the total variation. Genotype $\times$ location $(\mathrm{G} \times \mathrm{L})$ interaction across carotenoids was not significant and accounted only $10.3-17.5 \%$ of the total sum of square. Across locations, $\mathrm{BC}$ varied from 0.64 to $17.24 \mu \mathrm{g} / \mathrm{g}$, while $\mathrm{BCX}$ and proA ranged from 0.45 to $6.84 \mu \mathrm{g} / \mathrm{g}$ and 0.86 to $20.46 \mu \mathrm{g} / \mathrm{g}$, respectively.

All the nine normal hybrids lacking $c r t R B 1$-favourable allele, and check for grain yield potential, had low BC $(0.64-2.73 \mu \mathrm{g} / \mathrm{g}), \mathrm{BCX}(0.45-3.67 \mu \mathrm{g} / \mathrm{g})$ and proA $(0.86-3.98$ $\mu \mathrm{g} / \mathrm{g}$ ) compared to $\mathrm{crtRB} 1$-based hybrids (BC: $3.52-17.24 \mu \mathrm{g} / \mathrm{g}, \mathrm{BCX}: 2.25-6.84 \mu \mathrm{g} / \mathrm{g}$, and proA: $5.10-20.46 \mu \mathrm{g} / \mathrm{g})$. The mean proA among the $c r t R B 1$-based hybrids was 10.63 $\mu \mathrm{g} / \mathrm{g}$ compared to $2.73 \mu \mathrm{g} / \mathrm{g}$ among the normal hybrids. LUT (9.60-31.03 $\mu \mathrm{g} / \mathrm{g}), \mathrm{ZEA}$ $(1.24-12.73 \mu \mathrm{g} / \mathrm{g})$ and TC $(20.60-64.02 \mu \mathrm{g} / \mathrm{g})$ also showed wide variation among all hybrids (Table S1*). However, mean LUT and ZEA were comparable among the experimental (LUT: $22.30 \mu \mathrm{g} / \mathrm{g}$ and ZEA: $6.90 \mu \mathrm{g} / \mathrm{g}$ ) and normal hybrids (LUT: $19.39 \mu \mathrm{g} / \mathrm{g}$ and ZEA: $4.72 \mu \mathrm{g} / \mathrm{g})$, respectively. However, mean TC were among crtRB1-based (41.85 $\mu \mathrm{g} / \mathrm{g})$ were significantly higher than the normal hybrids $(27.12 \mu \mathrm{g} / \mathrm{g})$, respectively.

Table 2. Pooled ANOVA for various carotenoids fractions among 35 maize hybrids

\begin{tabular}{|l|r|c|c|c|c|c|c|}
\hline \multirow{2}{*}{\multicolumn{1}{c|}{ Source of variation }} & \multirow{2}{*}{ df } & \multicolumn{6}{c|}{ MSS } \\
\cline { 3 - 9 } & & BC & BCX & proA & LUT & ZEA & TC \\
\hline Location & 2 & 6.59 & 0.96 & 6.08 & $268 * *$ & $29.37 * *$ & $565.95 * *$ \\
\hline Genotype & 34 & $130 * *$ & $20.01 * *$ & $182 * *$ & $143 * *$ & $66.69 * *$ & $778.34 * *$ \\
\hline Genotype $\times$ Location & 68 & 14.32 & 1.78 & 18.19 & 14.98 & 4.19 & 60.49 \\
\hline Pooled error & 102 & 2.32 & 1.28 & 3.4 & 7.17 & 0.90 & 20.65 \\
\hline
\end{tabular}

df: Degrees of freedom, MSS: Mean Sum of Squares, BC: $\beta$-carotene, BCX: $\beta$-cryptoxanthin, proA: provitamin-A, LUT: Lutein, ZEA: Zeaxanthin, TC: Total Carotenoids

*Further details about the Electronic Supplementary Material (ESM) can be found at the end of the article. 


\section{Proportion of carotenoids}

Normal hybrids revealed higher proportion of mean LUT (72\%), followed by ZEA (17\%), $\mathrm{BC}(6 \%)$, and BCX (5\%) (Fig. 1). The study also revealed that non-proA carotenoids had major share $(91 \%)$ than the carotenoids with proA activity $(9 \%)$. However, crtRB 1-based hybrids possessed significantly higher proportion of BC $(21 \%)$ and BCX $(10 \%)$ compared to normal maize, and had relatively lower proportion of LUT (53\%) and ZEA (16\%) (Fig. 1). In PROAH-13, BC and BCX constituted 33\% and 12\% of the TC. Similar high proportion was also observed in PROAH-11, PROAH-17, PROAH-21, PROAH-24 and Pusa Vivek QPM9 Improved. Non-proA carotenoids in these hybrids were significantly lesser than the normal hybrids, and comprised $55-60 \%$ of the TC as compared to HQPM5 and HM9 where it was 96\% and 95\%, respectively.
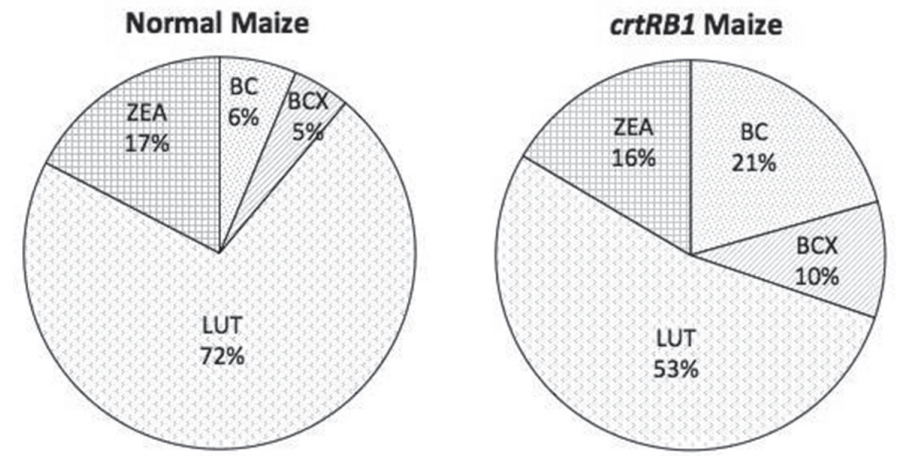

Figure 1. Relative proportion of carotenoids in normal- and crtRB1-based maize hybrids. BC: $\beta$-carotene, BCX: $\beta$-cryptoxanthin, proA: provitamin-A, LUT: Lutein, ZEA: zeaxanthin

\section{Association among carotenoids}

Among normal hybrids, positive correlations of proA with $\mathrm{BC}(\mathrm{r}=0.91)$, and $\mathrm{BCX}$ $(\mathrm{r}=0.81)$ were observed (Table 3$)$. However, much stronger relationship among $\mathrm{BC}$, $\mathrm{BCX}$ and proA was observed among the $\mathrm{crtRB} 1$-based hybrids $(\mathrm{r}=0.90-0.99)$. BC, BCX and proA did not show any correlation with LUT across both normal and proA rich hybrids. In normal maize, BC had negative association with ZEA $(\mathrm{r}=-0.65)$, while it was positive among $\operatorname{crtRB} 1$-based hybrids. BCX showed positive correlation with ZEA and it was not observed in case of crtRB1-based hybrids. LUT had positive correlation with ZEA in both type of hybrids although the relationship was much stronger in normal hybrids $(\mathrm{r}=0.91)$ than proA rich hybrids $(\mathrm{r}=0.63)$. BC, BCX and proA exhibited positive relationships with TC, but the same was absent in normal maize. LUT and ZEA both showed positive correlations with TC, although it was stronger in case of normal hybrids. No association was observed between grain yield with any of the carotenoids among both normal proA rich hybrids (Table 3 ). 
Table 3. Association among different fractions of kernel carotenoids and grain yield

\begin{tabular}{|c|c|c|c|c|c|c|c|}
\hline Trait & Type of hybrid & $\mathrm{BCX}$ & proA & LUT & ZEA & $\mathrm{TC}$ & YLD \\
\hline \multirow{2}{*}{$\mathrm{BC}$} & Normal & 0.50 & $0.91 * *$ & -0.54 & $-0.65^{*}$ & -0.40 & -0.54 \\
\hline & crtRB1-based & $0.90 * *$ & $0.99 * *$ & 0.12 & 0.19 & $0.64 * *$ & -0.08 \\
\hline \multirow{2}{*}{$\mathrm{BCX}$} & Normal & & $0.81 * *$ & 0.10 & 0.16 & 0.36 & -0.10 \\
\hline & crtRB1-based & & $0.93 * *$ & 0.22 & $0.37 *$ & $0.73 * *$ & -0.01 \\
\hline \multirow{2}{*}{ proA } & Normal & & & -0.32 & -0.36 & -0.10 & -0.41 \\
\hline & crtRB1-based & & & 0.14 & 0.22 & $0.67 * *$ & -0.07 \\
\hline \multirow{2}{*}{ LUT } & Normal & & & & $0.91 * *$ & $0.96 * *$ & 0.50 \\
\hline & crtRB1-based & & & & $0.63 * *$ & $0.78 * *$ & -0.18 \\
\hline \multirow{2}{*}{ ZEA } & Normal & & & & & $0.93 * *$ & 0.46 \\
\hline & crtRB1-based & & & & & $0.77 * *$ & -0.30 \\
\hline \multirow{2}{*}{$\mathrm{TC}$} & Normal & & & & & & 0.43 \\
\hline & crtRB1-based & & & & & & -0.22 \\
\hline
\end{tabular}

*,**significant at 0.05 and 0.01 level, respectively.

\section{Identification of promising hybrids}

Considering three locations, PROAH-13 [BC $(17.24 \mu \mathrm{g} / \mathrm{g}), \mathrm{BCX}(6.44 \mu \mathrm{g} / \mathrm{g})$ and proA $(20.46 \mu \mathrm{g} / \mathrm{g})$ ] and PROAH-21 [BC $(14.93 \mu \mathrm{g} / \mathrm{g}), \mathrm{BCX}(6.16 \mu \mathrm{g} / \mathrm{g})$, proA $(18.01 \mu \mathrm{g} / \mathrm{g})$ ] possessed highest mean; and found better than the proA rich "Pusa Vivek QPM9 Improved" hybrid used as check for proA content. This hybrid was introgressed with favourable allele of $c r t R B 1$ and commercially released in India. Other high proA rich hybrids were PROAH-17, PROAH-11, PROAH-23, PROAH-24 and PROAH-3. APH27, a proA rich experimental hybrid under evaluation in national testing possessed $10.80 \mu \mathrm{g} / \mathrm{g}$ of BC, $4.91 \mu \mathrm{g} / \mathrm{g}$ of BCX and $13.26 \mu \mathrm{g} / \mathrm{g}$ of proA. Besides, PROAH-17 (LUT: $31.03 \mu \mathrm{g} / \mathrm{g}$, ZEA: $12.51 \mu \mathrm{g} / \mathrm{g}$ ), PROAH-21 (LUT: $30.20 \mu \mathrm{g} / \mathrm{g}$, ZEA: $12.73 \mu \mathrm{g} / \mathrm{g}$ ) and PROAH-3 (LUT: $30.85 \mu \mathrm{g} / \mathrm{g}$, ZEA: $12.33 \mu \mathrm{g} / \mathrm{g}$ ) also had higher non-proA fraction than the normal hybrids.

The mean grain yield of proA rich hybrids $(6794 \mathrm{~kg} / \mathrm{ha}$ ) was comparable to the normalhybrids (6961 kg/ha) (Table S1). Among the proA rich hybrids, PROAH-24 possessed $7540 \mathrm{~kg} / \mathrm{ha}$ of grain yield across locations followed by PROAH-11 (7299 kg/ha), PROAH-23 (7035 kg/ha), PROAH-21 (6975 kg/ha), PROAH-13 (6953 kg/ha), PROAH-17 (6586 kg/ha) and PROAH-3 (6400 kg/ha). These hybrids possessed significantly higher grain yield over proA rich hybrids (Pusa Vivek QPM9 Improved: $5846 \mathrm{~kg} / \mathrm{ha}$, APH27: $5752 \mathrm{~kg} / \mathrm{ha}$ ), and were comparable with the normal hybrids.

\section{Discussion}

The study revealed that variation in carotenoids caused due to genotypes was the major contributing factors, while effects of location and $G \times L$ were of minor magnitude. Similar results of were earlier reported in tropical-inbreds (Menkir et al. 2008) as well as 
temperate-inbreds (Kurilich and Juvik 1999) and -hybrids (Egesel et al. 2003). Sub-tropically adapted inbreds (Vignesh et al. 2012; Muthusamy et al. 2015a,c) and hybrids (Muthusamy et al. 2016) evaluated in India also revealed the similar trend. Results thus indicate maize hybrids rich in proA developed at one location can be grown successfully across different zones.

Marked differences in carotenoids is due to absence of favourable allele of $\operatorname{crtRB} 1$ in normal hybrids and presence of the same among experimental hybrids. The favourable allele is rare and occurs in low frequency $(3.38 \%)$ in the maize germplasm (Muthusamy et al. 2015b). CrtRB1 located on chromosome 10 codes $\beta$-carotene hydroxylase protein that converts $\mathrm{BC}$ to $\mathrm{BCX}$, and $\mathrm{BCX}$ to $\mathrm{ZEA}$. However, favourable allele of $\operatorname{crtRB} 1$ partially blocks the process of hydroxylation of $\mathrm{BC}$ and $\mathrm{BCX}$ into further components, thereby leading to the increase of concentration of proA (Yan et al. 2010). The favourable allele of $\operatorname{crtRB} 1$ gene causes reduced transcript expression followed by less enzymatic activity of $\beta$-carotene hydroxylase. Muthusamy et al. (2014) introgressed favourable allele of $\operatorname{crtRB1}$ into parental lines of four hybrids and recorded proA as high as $21.7 \mu \mathrm{g} / \mathrm{g}$, compared to $2.6 \mu \mathrm{g} / \mathrm{g}$ in the original hybrid. Zunjare et al. (2018a) also improved four popular quality protein maize hybrids for proA by introgressing favourable allele of crtRB1 along with lycopene epsilon cyclase (lcyE).

However, wide genetic variation was also observed among the $\operatorname{crtRB} 1$-based hybrids. Various genes in the carotenoid biosynthesis pathway might also have influenced its accumulation (Choudhary et al. 2014, 2015). Phytoene synthasel (Y1 or Psyl) and lcyE have also been shown to regulate the accumulation of proA compounds. Further Vignesh et al. (2013) and Zunjare et al. (2018b) reported novel SNP and InDel variations in $c r t R B$ land $l c y E$, respectively that distinguished high proA genotypes with low proA genotypes. Wong et al. (2004) and Chander et al. (2008) also identified several quantitative trait loci (QTL) governing accumulation of caroteoids in maize grains.

Proportion of non-proA carotenoids especially LUT in normal hybrids was higher compared to proA carotenoids, suggesting that higher flux of lycopene towards $\alpha$-branch than the $\beta$-branch of the pathway. Although, in $\operatorname{crtRB} 1$-based hybrids synthesis of $\mathrm{BC}$ and $\mathrm{BCX}$ in the $\beta$-branch is enhanced, LUT remained the most predominant fractions. In normal, ZEA constituted the higher proportion next to lutein. Interestingly, the proportion of ZEA remained same proA rich hybrids, although proportion of $\mathrm{BC}$ was more. This could be because of role of ZEA in synthesis of abscisic acid (ABA) which is vital for abiotic stress tolerance of the plants.

Correlation analyses revealed strong and positive association between LUT and ZEA (Muthusamy et al. 2016). LUT being product of $\alpha$-branch of the carotenoid biosynthesis pathway showed weak and non-significant correlation with $\mathrm{BC}, \mathrm{BCX}$ and proA carotenoids of $\beta$-branch of the pathway. As BCX is precursor in biosynthesis of ZEA in the $\beta$-branch of the pathway (Howitt and Pogson 2006), and thus it is obvious that ZEA would be positively correlated with BCX (Muthusamy et al. 2016). However, in normal hybrids, ZEA was not correlated with BCX. Among crtRB1-based experimental hybrids, $\mathrm{BC}, \mathrm{BCX}$ and proA exhibited positive correlations with $\mathrm{TC}$, thereby suggesting enhancement in proA activity leads to enhancement overall carotenoids. This could be the reasons 
of higher mean TC in experimental hybrids. Non-correlation of LUT and ZEA with BC and proA indicated that it is possible to develop proA rich hybrids with higher antioxidant activities as well. PROAH-17, PROAH-21 and PROAH-3 are the examples where they possessed $>43 \mu \mathrm{g} / \mathrm{g}$ of non-proA carotenoids along with $>12 \mu \mathrm{g} / \mathrm{g}$ of proA carotenoids. Therefore, simultaneous increase in the levels of both proA and non-proA carotenoids could be undertaken in maize biofortification programme.

The results of our study also indicated that there was no association between carotenoid components and grain yield (Muthusamy et al. 2016). Several hybrids with high proA identified in the study also had higher grain yield, and were at par with the normal hybrids. Muthusamy et al. (2014) and Zunjare et al. (2018a) developed proA rich hybrids having similar grain yield potential to their original version. 'Pusa Vivek QPM9 Improved' is a proA rich version of normal hybrid 'Vivek QPM9', and was developed through MAS (Muthusamy et al. 2014). The reconstituted version had similar grain yield potential of its original version at multi-locations under AICRP, and has been released for commercial cultivation. This clearly suggests that no yield penalty unlike high protein and oil is associated with proA enhancement. Some of the proA rich hybrids identified in the study were significantly better than released proA rich hybrid 'Pusa Vivek QPM9 Improved' in India for grain yield potential. Germplasm base for proA in India is quite narrow as breeding programme for proA enrichment is only 6-7 years old and only few breeding centres are involved in the trait improvement. Considering this, identified promising hybrids holds great potential for providing sustainable and cost-effective solution to VAD.

\section{Conclusions}

The study assessed a set of newly developed crtRB1-based hybrids for different carotenoid fractions and grain yield potential through multi-location evaluation. They possessed significantly higher proA compared to normal hybrids. Some of the promising proA rich hybrids also had high non-proA fraction having antioxidant activity. Grain yield potential of the proA hybrids were at par with the normal hybrids. Promising hybrids identified here assumes significance in maize biofortification programme.

\section{Acknowledgements}

We are thankful to the ICAR-Indian Agricultural Research Institute, New Delhi for financial support. The authors thank CIMMYT, Mexico and AICRP centres for providing crtRB1-basedinbreds. The help of Mr. Manish Kapasia in managing the field operations and pollination programme is acknowledged.

\section{References}

Bouis, H.E., Saltzman, A. 2017. Improving nutrition through biofortification: A review of evidence from HarvestPlus, 2003 through 2016. Global Food Secur. 12:49-58. 
Chander, S., Guo, Y.Q., Yang, X.H., Zhang, J., Lu, X.Q., Yan, J.B. 2008. Using molecular markers to identify two major loci controlling carotenoid contents in maize grain. Theor. Appl. Genet. 116:223-233.

Choudhary, M., Hossain, F., Muthusamy, V., Thirunavukkarasu, N., Saha, S., Pandey, N., Jha, S.K., Gupta, H.S. 2015. Microsatellite marker-based genetic diversity analyses of novel maize inbreds possessing rare allele of $\beta$-carotene hydroxylase ( $\mathrm{crtRBI}$ ) for their utilization in $\beta$-carotene enrichment. J. Plant Biochem. Biotech. 25:12-20.

Choudhary, M., Muthusamy, V., Hossain, F., Thirunavukkarasu, N., Pandey, N., Jha, S.K., Gupta, H.S. 2014. Characterization of $\beta$-carotene rich MAS-derived maize inbreds possessing rare genetic variation in $\beta$-carotene hydroxylase gene. Indian J. Genet. 74:620-623.

Egesel, C.O., Wong, J.C., Lambert, R.J., Rocheford, T.R. 2003. Gene dosage effects on carotenoid concentration in maize grain. Maydica 48:183-190.

Fraser, P.D., Bramley, P.M. 2004. The biosynthesis and nutritional uses of carotenoids. Prog. Lip. Res. 43:228265.

Global Nutrition Report. 2017. Retrived from website https://www.globalnutrition report.org.

Gupta, H.S., Hossain, F., Muthusamy, V. 2015. Biofortification of maize: An Indian perspective. Indian J. Genet. 75:1-22.

Howitt, C.A., Pogson, B.J. 2006. Carotenoid accumulation and function in seeds and non-green tissues. PlantCell Environ. 29:435-445.

IFPRI 2016. Retrived from website, https://www.ifpri.org/publication/donor-progress-2016-nutrition-growthtracking-table

Kurilich, A.C., Juvik, J.A. 1999. Quantification of carotenoid and tocopherol antioxidants in Zea mays. J. Agric. Food Chem. 47:1948-1955.

Menkir, A., Brown, R.L., Bandyopadhyay, R., Cleveland, T.E. 2008. Registration of six tropical maize germplasm lines with resistance to aflatoxin contamination. J. Plant Registrations 2:246-250.

Muthusamy, V., Hossain, F., Nepolean, T., Saha, S., Agrawal, P.K., Guleria, S.K., Gupta, H.S. 2015a. Genetic variability and inter-relationship of kernel carotenoids among indigenous and exotic maize (Zea mays L.) inbreds. Cereal Res. Comm. 43:567-578.

Muthusamy, V., Hossain, F., Thirunavukkarasu, N., Pandey, N., Vishwakarma, A.K., Saha, S., Gupta, H.S. 2015c. Molecular characterization of exotic and indigenous maize inbreds for biofortification with kernel carotenoids. Food Biotechnol. 29:276-295.

Muthusamy, V., Hossain, F., Thirunavukkarasu, N., Choudhary, M., Saha, S., Bhat, J.S., 2014. Development of $\beta$-carotene rich maize hybrids through marker-assisted introgression of $\beta$-carotene hydroxylase allele. PLoS One 9:1-22.

Muthusamy, V., Hossain, F., Thirunavukkarasu, N., Saha, S., Agrawal, P.K., Gupta, H.S. 2016. Genetic analyses of kernel carotenoids in novel maize genotypes possessing rare allele of $\beta$-carotene hydroxylase gene. Cereal Res. Commun. 44:669-680.

Muthusamy, V., Hossain, F., Thirunavukkarasu, N., Saha, S., Gupta, H.S. 2015b. Allelic variations for lycopene- $\varepsilon$-cyclase and $\beta$-carotene hydroxylase genes in maize inbreds and their utilization in $\beta$-carotene enrichment programme. Cogent Food Agric. 1.

Neeraja, C.N., Babu, V.R., Ram, S., Hossain, F., Hariprasanna, K., Rajpurohit, B.S. 2017. Biofortification in cereals:progress and prospects. Curr. Sci. 113:1050-1057.

Sarika, K., Hossain, F., Muthusamy, V., Zunjare, R.U., Baveja, A., Goswami, R., Bhat, J.S., Saha, S., Gupta, H.S. 2018. Marker-assisted pyramiding of opaque 2 and novel opaque16 genes for further enrichment of lysine and tryptophan in sub-tropical maize. Plant Sci. 272:142-152.

Vignesh, M., Nepolean, T., Hossain, F., Singh, A.K., Gupta, H.S. 2013. Sequence variation in 3'UTR region of crtRB1 gene and its effect on $\beta$-carotene accumulation in maize kernel. J. Plant Biochem. Biotech. 22:401408.

Vignesh, M., Hossain, F., Nepolean, T., Supradip, S., Agrawal, P.K., Guleria, S.K. 2012. Genetic variability for kernel $\beta$-carotene and utilization of crtRB1 3'TE gene for biofortification in maize (Zea mays L.). Indian J. Genet. 72:189-194. 
Wong, J.C., Lambert, R.J., Wurtzel, E.T., Rocheford, T.R. 2004. QTL and candidate genes phytoene synthase and $\zeta$-carotene desaturase associated with the accumulation of carotenoids in maize. Theor. Appl. Genet. 108:349-359.

Yadava, D.K., Choudhury, P.R., Hossain, F., Kumar, D. 2017. Biofortified varieties:sustainable way to alleviate malnutrition. ICAR, New Delhi. pp. 1-32.

Yan, J., Kandianis, C.B., Harjes, C.E., Bai, L., Kim, E.H., Yang, X. 2010. Rare genetic variation at Zea mays crtRB1 increases $\beta$-carotene in maize grain. Nat. Genet. 42:322-327.

Zunjare, R.U., Chhabra, R., Hossain, F., Baveja, A., Muthusamy, V., Gupta, H.S. 2018b. Molecular characterization of 5' UTR of the lycopene epsilon cyclase $(l c y E)$ gene among exotic and indigenous inbreds for its utilization in maize biofortification. 3Biotech 8:75.

Zunjare, R.U., Chhabra, R., Hossain, F., Muthusamy, V., Baveja, A., Gupta, H.S. 2018c. Development and validation of multiplex-PCR assay for simultaneous detection of rare alleles of $\operatorname{crtRB} 1$ and $l c y E$ governing higher accumulation of provitamin A in maize kernel. J. Plant Biochem.Biotechnol. 2:208-214.

Zunjare, R.U., Hossain, F., Muthusamy, V., Baveja, A., Chauhan, H.S., Bhat, J.S., Thirunavukkarasu, N., Saha, S., Gupta, H.S. 2018a. Development of biofortified maize hybrids through marker-assisted stacking of $\beta$-carotene hydroxylase, lycopene- $\varepsilon$-cyclase and opaque2 genes. Front. Plant Sci. 9:178.

Zunjare, R.U., Hossain, F., Muthusamy, V., Baveja, A., Chauhan, H.S., Thirunavukkarasu, N., Saha, S., Gupta, H.S. 2017. Influence of rare alleles of $\beta$-carotene hydroxylase and lycopene epsilon cyclase genes on accumulation of provitamin A carotenoids in maize kernels. Plant Breed. 136:872-880.

\section{Electronic Supplementary Material (ESM)}

Electronic Supplementary Material (ESM) associated with this article can be found at the website of CRC at http://www.akademiai.com/content/120427/

Electronic Supplementary Table S1. Performance of 35 maize hybrids for kernel carotenoids and grain yield across locations 